\title{
PERAN BRAND AWARENESS MEMEDIASI DAYA TARIK IKLAN ONLINE TERHADAP NIAT BELI "MADANTY FASHION"
}

\author{
I Ketut Alex Mahardika ${ }^{1}$ \\ I Wayan Santika ${ }^{2}$
}

\author{
Fakultas Ekonomi dan Bisnis Universitas Udayana, Bali, Indonesia ${ }^{1,2}$ \\ email: alexmahardika22@gmail.com
}

\begin{abstract}
ABSTRAK
Perusahaan perlu melakukan pendekatan kepada konsumen dalam upaya membentuk brand awareness di benak konsumen melalui iklan agar konsumen mudah mengenali merek suatu produk diantara merek lainnya. Konsumen cenderung membeli merek suatu produk yang masih dikenal bagi mereka.Tujuan penelitian ini adalah untuk menjelaskan peran brand awareness memediasi pengaruh daya tarik iklan online terhadap niat beli Madanty Fashion. Dalam penelitian ini teknik pemilihan sampel menggunakan teknik Purposive Sampling. Jumlah sampel yang ditentukan adalah sebanyak 140 orang. Metode pengumpulan data menggunakan instrumen penelitian berupa kuesioner. Teknik analisis yang digunakan adalah analisis statistik deskriptif, analisis jalur dan uji sobel. Hasil penelitian ini menunjukan bahwa, variabel daya tarik iklan online berpengaruh positif dan signifikan terhadap brand awareness begitu pula terhadap niat beli. Variabel brand awareness juga berpengaruh positif dan signifikan terhadap niat beli. Variabel brand awareness memediasi daya tarik iklan online terhadap niat beli secara parsial.
\end{abstract}

Kata kunci: daya tarik iklan online, brand awareness, niat beli.

\begin{abstract}
Companies need to approach consumers in an effort to form brand awareness in the minds of consumers through advertising so that consumers can easily recognize the brand of a product among other brands. Consumers tend to buy a brand of a product that is still well known to them. The purpose of this study is to explain the role of brand awareness in mediating the effect of the attractiveness of online advertising on purchase intention of Madanty Fashion. In this study, the sample selection technique used purposive sampling technique. The number of samples determined was 140 people. The data collection method used a research instrument in the form of a questionnaire. The analysis technique used is descriptive statistical analysis, path analysis and sobel test. The results of this study indicate that the attractiveness of online advertising has a positive and significant effect on brand awareness as well as purchase intention. The brand awareness variable also has a positive and significant effect on purchase intention. The brand awareness variable partially mediates the attractiveness of online advertising to purchase intentions.

Keywords: attractiveness of online advertising, brand awareness, purchase intention.
\end{abstract}




\section{PENDAHULUAN}

Pesatnya perkembangan teknologi dan globalisasi mendorong pemasar untuk mengembangkan proses pemasarannya, khususnya di bidang online. Kegiatan atau proses pemasaran melalui media online seperti media sosial saat ini sudah mulai lumrah dan sering dilakukan. Hal ini terjadi karena pada media online, pemasar mampu menjangkau pasar yang lebih jauh dan lebih luas. Media online bisa digunakan sebagai media untuk mengkomunikasikan produk atau jasa kepada konsumen. Media online juga menjadi sarana berdiskusi dan membagi pengalaman tentang suatu merek oleh beberapa pengguna. Hal ini dipertegas oleh pandangan (Kotler, 2018) yang menyatakan bahwa kini perusahaan mampu menjangkau konsumen dengan komunikasi dua arah melalui media sosial, sehingga dapat membentuk perilaku konsumen dan kesadaran merek atas produk dan jasa yang ditawarkan. Salah satu media komunikasi yang berkembang saat ini dengan menggunakan media sosial adalah Instagram.

Menurut data yang dirilis Napoleon Cat, pada periode Januari-Mei 2020, pengguna Instagram di Indonesia mencapai 69,2 juta (69.270.000) orang (Cat, 2020). Menurut Napoleon Cat, kebanyakan pengguna Instagram adalah wanita yakni 50,8 persen dan berbeda tipis dengan pengguna laki-laki yakni 49,2 persen. Banyaknya persentase wanita sebagai pengguna Instagram merupakan peluang bagi pemasar menggunakan media ini untuk melakukan promosi, terutama pada produk-produk yang sesuai dengan karakter wanita yaitu fashion. Madanty Fashion merupakan salah satu usaha online yang bergerak di bidang fashion khususnya pakaian jadi untuk wanita. Terhitung mulai dari awal tahun 2019 Madanty Fashion memproduksi produknya sendiri, kemudian pada bulan Juli tahun 2019 Madanty Fashion fokus memasarkan produknya melalui media sosial Instagram. Melalui iklan pada media sosial Instagram, produk Madanty Fashion dapat ditemui dengan mudah oleh konsumen. Produk yang menjadi icon atau ciri khasnya adalah outer wanita, sejenis pakaian luaran yang dapat dipadukan dengan berbagai macam jenis pakaian lainnya. Konsumen dari Madanty Fashion cenderung didominasi oleh kaum millinneals yang sudah terbiasa berbelanja online dengan berbagai media sosial khususnya Instagram. Tercatat kurang dari kurun waktu 2 tahun, Madanty Fashion memiliki jumlah pengikut sebanyak 2.016 orang di Instagram. Hal tersebut menjadikan Madanty Fashion sebagai salah satu clothing online di Bali yang memiliki cukup banyak pengikut dengan hanya memasarkan produknya melalui media sosial Instagram.

Produk yang dipasarkan melalui media promosi iklan pada media sosial bertujuan untuk memperkenalkan dan menawarkan produk pada konsumen dengan segmentasi yang lebih luas. Iklan merupakan salah satu media promosi yang dapat digunakan sebagai alat untuk pengantar pesan yang bertujun untuk membentuk dan merubah perilaku konsumen (Fitri Anggraini Gunawan, 2014). Perhatian serta daya ingat dapat meningkat ketika konsumen menerima informasi dalam iklan. Perusahaan perlu melakukan pendekatan kepada konsumen dalam upaya membentuk kesadaran merek (Brand Awareness) di benak konsumen agar mudah mengenali merek suatu produk diantara merek lainnya (Dewa, 2015). Brand Awareness merupakan suatu daya ingat konsumen terhadap suatu produk 
yang telah melekat dalam benak konsumen akan suatu kebutuhan tertentu (Wicaksono \& Seminari, 2016).

Madanty Fashion melakukan periklanan dengan menayangkan produknya serta testimoni oleh para konsumennya. Sebagian besar masyarakat tidak mengetahui bahwa outer yang dipasarkan oleh Madanty Fashion dapat dicocokan dengan berbagai macam jenis pakaian. Masyarakat cenderung memiliki pengetahuan bahwa outer hanya dapat digunakan untuk acara formal saja. Rendahnya kesadaran akan berbagai macam penggunaan outer mengakibatkan rendahnya niat beli terhadap produk tersebut.

Niat membeli dapat digunakan untuk memprediksi perilaku yang akan datang. Artinya bila konsumen menunjukkan niat membeli yang tinggi, maka dapat diduga bahwa ia akan melakukan pembelian aktual. Pemasar berkepentingan untuk mengidentifikasi niat beli konsumen (Suprapti, 2010). Melalui pengidentifikasian niat beli konsumen maka produsen akan dapat untuk menentukan faktor-faktor apa saja yang dapat mempengaruhi niat beli konsumen tersebut yang selanjutnya dapat digunakan untuk menyusun strategi-strategi yang tepat

Untuk mengetahui faktor yang mempengaruhi persepsi konsumen terhadap produk Madanty Fashion, maka dilaksanakan penelitian yang menggunakan metode pra survei yang menyebar kuisioner sementara terhadap 20 orang responden yang berdomisili di kota Denpasar. Tabel 1 merupakan pernyataan pra survei melalui variabel daya tarik iklan online, brand awareness dan niat beli dengan menggunakan satu indikator pada masing-masing variabel. Variabel daya tarik iklan online menggunakan indikator keberadaan iklan, variabel brand awareness menggunakan indikator pengetahuan merek, dan variabel niat beli menggunakan indikator pencarian informasi produk. Berikut disajikan hasil pra survei yang telah dilakukan.

Tabel 1.

Hasil Pra-Survei

\begin{tabular}{|c|c|c|c|c|}
\hline \multirow[t]{2}{*}{ Variabel } & \multirow[t]{2}{*}{ Pernyataan } & \multicolumn{2}{|c|}{ Jawaban } & \multirow[t]{2}{*}{ Responder } \\
\hline & & Setuju & Tidak Setuju & \\
\hline $\begin{array}{c}\text { Daya Tarik } \\
\text { Iklan Online }\end{array}$ & $\begin{array}{l}\text { Saya merasa pernah melihat } \\
\text { iklan online dari Madanty } \\
\text { Fashion. }\end{array}$ & 14 & 6 & 20 \\
\hline $\begin{array}{c}\text { Brand } \\
\text { Awareness }\end{array}$ & $\begin{array}{l}\text { Saya memiliki wawasan } \\
\text { tentang produk yang dijual } \\
\text { oleh Madanty Fashion. }\end{array}$ & 9 & 11 & 20 \\
\hline Niat Beli & $\begin{array}{l}\text { Setelah melihat iklan online } \\
\text { dari Madanty Fashion, saya } \\
\text { ingin mencari informasi } \\
\text { tentang produk yang } \\
\text { ditawarkan. }\end{array}$ & 13 & 7 & 20 \\
\hline
\end{tabular}

Sumber : Hasil Pra Survei 
Berdasarkan Tabel 1. yang menunjukkan hasil dari pra survei, pernyataan "Saya merasa pernah melihat iklan online dari Madanty Fashion", 14 responden menjawab setuju dan 6 responden menjawab tidak setuju, hal ini menandakan responden yang berpartisipasi dalam pengisian kuesioner lebih banyak menyadari keberadan iklan yang ditayangkan oleh Madanty Fashion. Dari segi brand awareness, pada pernyataan "Saya memiliki wawasan tentang produk yang dijual oleh Madanty Fashion" 9 responden menjawab setuju dan 11 responden menjawab tidak setuju, hal ini menandakan responden yang berpartisipasi dalam pengisian kuesioner masih kurang mengetahui produk yang ditawarkan ataupun yang dijual oleh Madanty Fashion. Dari segi niat beli, pada pernyataan "Setelah melihat iklan online dari Madanty Fashion, saya ingin mencari informasi tentang produk yang ditawarkan" 13 responden menjawab setuju dan 7 responden menjawab tidak setuju, hal ini menandakan bahwa responden yang berpartisipasi dalam pengisian kuesioner memiliki keinginan untuk mencari informasi produk setelah melihat iklan online Madanty Fashion.

Berdasarkan latar belakang yang telaj dijabarkan, maka adapun pokok permasalahan pada penelitian ini yaitu: 1) Bagaimanakah pengaruh Daya Tarik Iklan Online terhadap Brand Awareness? 2) Bagaimanakah pengaruh Daya Tarik Iklan Online terhadap Niat Beli? 3) Bagaimakah pengaruh Brand Awareness terhadap Niat Beli? 4) Bagaimanakah peran Brand Awareness memediasi pengaruh Daya Tarik Iklan Online terhadap Niat Beli?

Tujuan dari penelitian ini antara lain: 1) Untuk menjelaskan Daya Tarik Iklan Online terhadap Brand Awareness; 2) Untuk menjelaskan Daya Tarik Iklan Online terhadap Niat Beli; 3) Untuk menjelaskan pengaruh Brand Awareness terhadap Niat Beli; 4) Untuk menjelaskan peran Brand Awareness memediasi pengaruh Daya Tarik Iklan Online terhadap Niat Beli.

Menurut Erdogmus \& Cicek (2012) pemasaran media sosial didefinisikan sebagai proses yang memberdayakan individu untuk mempromosikan situs web, produk, atau jasa mereka melalui saluran sosial online dan memasuki sebuah komunitas yang jauh lebih besar yang mungkin belum tersedia melalui saluran tradisional. Menurut (Bülbül \& Menon, 2010) daya tarik iklan digunakan untuk memengaruhi perasaan, membujuk, serta mempertahankan gambaran produk di benak konsumen. Daya tarik merupakan pendekatan yang diterapkan dalam iklan untuk membuat konsumen tertarik tehadap suatu produk (Nwankwo et al., 2013). Pada dunia periklanan menentukan daya tarik (advertising appeal) sudah pasti sangat diperlukan untuk menarik perhatian konsumen. Efektivitas iklan tergantung dari isi, eksekusi atau bagaimana iklan dalam menyampaikan pesan (Charanah \& Njuguna, 2015). Melalui pengiklanan konsumen akan lebih mengenal produk yang dimiliki oleh suatu perusahaan. Pengenalan produk tersebut kemudian akan menimbulkan kesadaran konsumen akan suatu merek.

Menurut (Shimp, 2014) brand awareness merupakan persoalan apakah nama merek tertentu muncul dalam ingatan ketika konsumen berpikir mengenai suatu kelompok produk tertentu dan terdapat kemudahan saat nama tersebut dimunculkan. Menurut Ehsan Malik et al. (2013) kesadaran merek (brand awareness) merupakan sebuah modal yang penting bagi perusahaan, karena 
merupakan salah satu faktor yang mempengaruhi perilaku konsumen dalam mengambil keputusan.

Niat beli menurut (Saad et al., 2012) adalah jenis keputusan yang mempelajari secara khusus mengapa konsumen membeli sebuah merek. Niat beli adalah evaluasi dan sikap konsumen terhadap produk dengan melihat faktor eksternal sehingga berdampak pada kesediaan konsumen untuk membeli produk (Wen \& Li, 2013). Niat beli sebagai suatu keinginan untuk dapat memiliki suatu produk apabila niat tersebut didorong oleh pengaruh akan mutu dan kualitas dari suatu produk dan adanya informasi yang mendukung keberadaan produk tersebut (Barr, 2007).

(Clark et al., 2009) menemukan efek positif yang signifikan dari pengeluaran iklan pada brand awareness. (Agustin Bayu Sugiardi, Dr. Harti, Dra, 2017) juga menyatakan bahwa iklan memiliki pengaruh positif dan signifikan terhadap brand awareness. Begitu pula dengan (Charanah \& Njuguna, 2015); (Herdana, 2015); (Sukma et al., 2015) yang menyatakan bahwa efektifitas iklan berpengaruh secara positif dan signifikan terhadap brand awareness. Berdasarkan pada hasil empiris dan penelitian terdahulu, maka dapat diajukan hipotesis sebagai berikut:

$\mathrm{H}_{1}$ : Daya Tarik Iklan Online berpengaruh positif dan signifikan terhadap Brand Awareness.

(Fitri Anggraini Gunawan, 2014) melakukan penelitian dengan hasil variabel iklan memiliki pengaruh positif dan signifikan terhadap niat beli. Pernyataan tersebut didukung oleh (Wibowo \& Nurhadi, 2017) yang juga mengatakan bahwa terdapat pengaruh positif efektivitas iklan terhadap niat beli konsumen. Begitu pula penelitian dari (Husein et al., 2016); (Nadu et al., 2014); (Huang, Ying-Fang Dang, 2014) menunjukan bahwa iklan berpengaruh positif dan signifikan terhadap niat beli. Berdasarkan pada hasil empiris dan penelitian terdahulu, maka dapat diajukan hipotesis sebagai berikut:

$\mathrm{H}_{2}$ : Daya Tarik Iklan Online berpengaruh positif dan signifikan terhadap Niat Beli.

(Iwan \& Nainggolan, 2017); (Petahiang et al., 2015) mengatakan bahwa brand awareness memiliki pengaruh yang positif dan signifikan dengan niat beli konsumen. Hasil penelitian yang senada juga dikemukakan oleh (Kristanto \& Karina M.R. Brahmana, 2016) yang menyatakan bahwa brand awareness berpengaruh positif dan signifikan terhadap niat beli suatu produk. Penelitian tersebut didukung oleh penelitian (Roozy et al., 2014) yang mengemukakan bahwa kesadaran merek (brand awareness) dapat mempengaruhi niat beli secara positif signifikan. Berdasarkan pada hasil empiris dan penelitian terdahulu, maka dapat diajukan hipotesis sebagai berikut:

$\mathrm{H}_{3}$ : Brand Awareness berpengaruh positif dan signifikan terhadap Niat Beli.

Penelitian (Prabawa et al., 2017) melibatkan variabel iklan, brand awareness, dan niat beli, yang menunjukkan bahwa brand awareness secara signifikan mampu memediasi hubungan antara iklan dengan niat beli. Penelitian serupa yang diteliti oleh (Susilo \& Semuel, 2015); (Yudhiartika \& Haryanto, 2012) menjelaskan bahwa brand awareness mampu memediasi hubungan iklan 
dengan niat beli secara positif dan signifikan. Berdasarkan pada hasil empiris dan penelitian terdahulu, maka dapat diajukan hipotesis sebagai berikut:

$\mathrm{H}_{4}$ : Brand Awareness secara signifikan memediasi pengaruh Daya Tarik Iklan Online terhadap Niat Beli.

\section{METODE PENELITIAN}

Penelitian ini menggunakan pendekatan kuantitatif berbentuk asosiatif untuk meneliti populasi atau sampel tertentu yang bertujuan untuk menguji hipotesis tertentu yang telah ditetapkan. Penelitian ini dilakukan di Kota Denpasar yang memiliki jumlah penduduk sekitar 947.100 orang pada tahun 2019 menurut Badan Pusat Statistik Provinsi Bali. Variabel bebas dalam penelitian ini adalah daya tarik iklan online $(\mathrm{X})$, variabel terikat dalam penelitian ini adalah niat beli $(\mathrm{Y})$ dan variabel mediasi dalam penelitian ini adalah brand awareness (M). Populasi dalam penelitian ini adalah seluruh masyarakat kota Denpasar yang menggunakan media sosial Instagram. Dalam penelitian ini teknik pemilihan sampel menggunakan teknik Purposive Sampling. Jumlah sampel yang ditentukan adalah sebanyak 140 orang.

Tabel 2.

Indikator Penelitian

\begin{tabular}{clll}
\hline Variabel & & \multicolumn{1}{c}{ Indikator } & \multicolumn{1}{c}{ Sumber } \\
\hline & $\mathrm{X}_{1}$ & Keberadaan Iklan & Djatnika (2007) dan \\
Daya Tarik Iklan & $\mathrm{X}_{2}$ & Ketertarikan Iklan & Wijaya (2011). \\
Online (X) & $\mathrm{X}_{3}$ & Manfaat Iklan & \\
\hline & $\mathrm{X}_{4}$ & Pesan Iklan & Humdiana (2005), Liwe \\
& $\mathrm{Y}_{1}$ & Pengenalan Merek & $(2013)$, dan Rangkuti \\
& $\mathrm{Y}_{2}$ & Pengetahuan Merek & $(2011)$. \\
Brand Awareness (M) & $\mathrm{Y}_{3}$ & Ciri Khas Merek & \\
& $\mathrm{Y}_{4}$ & Mengingat Merek & Schiffman dan Kanuk. \\
& $\mathrm{Y}_{5}$ & Pilihan Utama Merek & \\
\hline & $\mathrm{Y}_{1}$ & Pencarian Informasi Produk & \\
\hline \multirow{5}{*}{ Niat Beli (Y) } & $\mathrm{Y}_{2}$ & Mempertimbangkan Produk & $(2004)$. \\
& $\mathrm{Y}_{3}$ & Keinginan Mengetahui Produk & \\
& $\mathrm{Y}_{4}$ & Ketertarikan Memiliki Produk & \\
& $\mathrm{Y}_{5}$ & Melakukan Pembelian Produk & \\
\hline
\end{tabular}

Sumber : Penelitian sebelumnya

Jenis data dalam penelitian ini dibagi menjadi dua yakni data kuantitatif dan data kualitatif. Data kuantitatif berupa usia responden, jumlah pengikut Instagram Madanty Fashion, jumlah pengguna Instagram di Indonesia, dan jumlah penduduk di Kota Denpasar, sedangkan data kualitatif yang digunakan pada penelitian ini yaitu berupa respon atau pendapat responden terhadap butir-butir pernyataan yang diajukan pada kuesioner. Sumber data dalam penelitian ini dibagi menjadi dua yakni sumber primer dan sumber sekunder. Sumber primer dalam penelitian ini adalah responden, sedangkan sumber sekunder dalam penelitian ini diperoleh dari Badan Pusat Statistik Provinsi Bali, internet, media sosial Instagram, dan peneliti sebelumnya.

Metode pengumpulan data yang digunakan dalam penelitian ini adalah metode survey dengan menggunakan instrumen kuesioner. Kuesioner disebar 
secara langsung kepada responden melalui bantuan Google Docs. Responden akan mendapatkan link yang dapat diakses untuk mengisi kuesioner, selanjutnya responden mengisi butir-butir pertanyaan dan pernyataan yang diajukan pada kuesioner. Setelah itu, responden diminta untuk submit atas jawaban yang telah diisi. Setelah memperoleh seluruh hasil kuesioner yang diperlukan, selanjutnya data dikumpulkan untuk dapat dianalisis.

Teknik analisis yang digunakan pada penelitian ini adalah analisis statistik deskriptif dan analisis statistik inferensial. Analisis statistik deskriptif bertujuan untuk mengetahui karakteristik dan tanggapan para responden terhadap item-item instrumen yang digunakan. Dalam penelitian ini, statistik deskriptif mendeskripsikan tentang variabel-variabel yang digunakan menggunakan perhitungan rata-rata dan standar deviasi. Statistik inferensial digunakan untuk menjawab hipotesis. Dalam penelitian ini, statistik inferensial yang digunakan adalah Analasis Jalur dan Uji Sobel.

\section{HASIL DAN PEMBAHASAN}

Suatu instrumen dikatakan valid jika korelasi antara skor faktor dengan skor total bernilai positif dan nilainya lebih dari $0,30(\mathrm{r}>0,3)$. Hasil pengujian validitas dapat dilihat pada Tabel 3.

Tabel 3.

Hasil Uji Validitas

\begin{tabular}{cccc}
\hline No & Variabel & Item Pertanyaan & $\begin{array}{c}\text { Korelasi Item } \\
\text { Total }\end{array}$ \\
\hline \multirow{4}{*}{1} & Daya Tarik Iklan & Keberadaan Iklan & 0,591 \\
& Online (X) & Ketertarikan Iklan & 0,798 \\
& & Manfaat Iklan & 0,886 \\
& Pesan Iklan & 0,841 \\
\hline \multirow{4}{*}{2} & Brand Awareness & Pengenalan Merek & 0,654 \\
& $(\mathrm{M})$ & Pengetahuan Merek & 0,854 \\
& & Ciri Khas Merek & 0,912 \\
& & Mengingat Merek & 0,863 \\
& & Pilihan Utama Merek & 0,855 \\
\hline \multirow{4}{*}{3} & Niat Beli (Y) & Pencarian Informasi Produk & 0,864 \\
& & Mempertimbangkan Produk & 0,860 \\
& & Keinginan Mengetahui Produk & 0,879 \\
& & Ketertarikan Memiliki Produk & 0,874 \\
& & Melakukan Pembelian Produk & 0,954 \\
\hline
\end{tabular}

Sumber: Hasil pengolahan data primer, 2020

Tabel 3. menunjukkan bahwa hasil uji validitas seluruh variabel memiliki nilai koefisien korelasi dengan skor total seluruh item pernyataan lebih besar dari 0,30. Hal ini menunjukkan bahwa, butir-butir pernyataan dalam instrumen penelitian tersebut valid.

Suatu instrumen dapat dikatakan reliabel, jika instrumen tersebut memiliki nilai Alpha Cronbach lebih dari 0,60. Adapun hasil dari uji reliabilitas dapat ditunjukkan pada Tabel 4. 
Tabel 4.

Hasil Uji Reliabilitas

\begin{tabular}{llc}
\hline No & \multicolumn{1}{c}{ Variabel } & Cronbach's Alpha \\
\hline 1 & Daya Tarik Iklan Online $(\mathrm{X})$ & 0,774 \\
2 & Brand Awareness $(\mathrm{M})$ & 0,888 \\
3 & Niat Beli (Y) & 0,924 \\
\hline \multicolumn{2}{l}{ Sumber: } & Hasil pengolahan data primer, 2020
\end{tabular}

Tabel 4. menunjukkan bahwa hasil uji reliabilitas pada setiap variabel memiliki nilai koefisien Alpha Cronbach lebih dari 0,6. Hal ini dapat dikatakan bahwa, semua variabel dalam penelitian ini adalah reliabel.

Responden penelitian digambarkan secara umum dengan menyajikan karakteristiknya yang dilihat dari umur, jenis kelamin dan pendidikan formal terakhir.

Berdasarkan hasil analisis karakteristik responden berdasarkan umur, diperoleh hasil yang dijabarkan sebagai berikut.

Tabel 5.

Karakteristik Responden Beradasrkan Umur

\begin{tabular}{clcc}
\hline No & Umur (Tahun) & Jumlah (Orang) & Jumlah (Persentase \%) \\
\hline 1 & $17-24$ & 127 & 90,7 \\
2 & $25-30$ & 12 & 8,6 \\
3 & $>30$ & 1 & 0,7 \\
\hline & Jumlah & 140 & 100 \\
\hline
\end{tabular}

Sumber: Hasil pengolahan data primer, 2020

Tabel 5. menunjukkan bahwa responden dengan usia 17-24 tahun yang paling mendominasi diantara usia lainnya yaitu 127 orang atau 90,7\%, Hal ini menunjukan bahwa responden yang berpartisipasi dalam pengisisian kuesioner berdasarkan umur yaitu sebagian besar dari umur 17-24 tahun.

Berdasarkan hasil analisis karakteristik responden berdasarkan jenis kelamin, diperoleh hasil yang dijabarkan sebagai berikut.

Tabel 6.

Karakteristik Responden Berdasarkan Jenis Kelamin

\begin{tabular}{clcc}
\hline No & Jenis Kelamin & Jumlah (Orang) & Jumlah (Persentase \%) \\
\hline 1 & Laki-laki & 23 & 16,4 \\
2 & Perempuan & 117 & 83,6 \\
\hline & Jumlah & 140 & 100 \\
\hline
\end{tabular}

Sumber: Hasil pengolahan data primer, 2020

Tabel 6. menunjukkan bahwa responden dengan jenis kelamin perempuan lebih mendominasi dengan jumlah 117 orang atau 83,6\%, sedangkan responden dengan jenis kelamin laki-laki sebanyak 23 orang atau 16,4\%. Hal ini menunjukan bahwa responden yang berpartisipasi dalam pengisisian kuesioner berdasarkan jenis kelamin didominasi oleh perempuan.

Berdasarkan hasil analisis karakteristik responden berdasarkan pendidikan formal terakhir, diperoleh hasil yang dijabarkan sebagai berikut. 
Tabel 7.

Karakteristik Responden Berdasarkan Pendidikan Formal Terakhir

\begin{tabular}{clcc}
\hline No & Pendidikan Formal Terakhir & Jumlah (Orang) & Jumlah (Persentase \%) \\
\hline 1 & SMA/SMK/Sederajat & 94 & 67,1 \\
2 & D3 & 9 & 6,4 \\
3 & S1 & 34 & 24,3 \\
4 & S2 & 3 & 2,1 \\
\hline & Jumlah & 140 & 100 \\
\hline
\end{tabular}

Sumber: Hasil pengolahan data primer, 2020

Tabel 7. menunjukkan bahwa responden dengan pendidikan formal terakhir SMA/SMK/Sederajat yang paling mendominasi diantara pendidikan formal lainnya yaitu sebanyak 94 orang atau $67,1 \%$, sedangkan, responden yang paling sedikit adalah responden dengan pendidikan formal terakhir S2 yakni 3 orang atau $2,1 \%$. Hal ini menunjukan bahwa responden yang berpartisipasi dalam pengisisian kuesioner berdasarkan pendidikan formal terakhir yaitu SMA/SMK/Sederajat.

Pengumpulan data melalui kuesioner terdiri atas pernyataan responden berdasarkan masing-masing variabel, yaitu: daya tarik iklan online, brand awareness, dan niat beli. Penilaian responden mengenai variabel-variabel dalam penelitian perlu dilakukan penentuan distribusi frekuensi berdasarkan nilai intervalnya, adapun untuk menentukan nilai interval yang dimaksud adalah sebagai berikut.

$$
\text { Interval }=\frac{\text { nilai tertinggi }- \text { nilai terendah }}{\text { Jumlah } \text { kelas }}=\frac{5-1}{5}=0,80
$$

Skor pada penelitian ini memiliki nilai tertinggi maksimal 5 dan terendah minimal 1 sehingga, dapat disusun kriteria pengukuran sebagai berikut.

Tabel 8.

Kriteria Pengukuran Deskripsi Variabel Penelitian

\begin{tabular}{ccccc}
\hline No & Skala Pengukuran & $\begin{array}{c}\text { Daya Tarik Iklan } \\
\text { Online }\end{array}$ & Brand Awareness & Niat Beli \\
\hline 1 & $1,00-1,80$ & Sangat Rendah & Sangat Rendah & Sangat Rendah \\
2 & $1,81-2,60$ & Rendah & Rendah & Rendah \\
3 & $2,61-3,40$ & Cukup Rendah & Cukup Rendah & Cukup Rendah \\
4 & $3,41-4,20$ & Tinggi & Tinggi & Tinggi \\
5 & $4,21-5,00$ & Sangat Tinggi & Sangat Tinggi & Sangat Tinggi \\
\hline
\end{tabular}

Sumber: Ghozali, 2016

Dalam penelitian ini, variabel daya tarik iklan online merupakan variabel bebas yang diukur dengan menggunakan 4 pernyataan yang berhubungan dengan daya tarik iklan online Madanty Fashion. Tabel 9 menunjukkan daya tarik iklan online secara keseuluruhan sangat tinggi, hal ini dapat dilihat dari keseluruhan rata-rata nilai daya tarik iklan online yaitu 4,45. Nilai rata-rata tertinggi pada pernyataan "Saya merasa pernah melihat iklan dari Madanty Fashion". Hal ini menunjukkan bahwa, responden yang berpartisipasi dalam pengisisan kuesioner pernah melihat iklan online dari Madanty Fashion. 


\begin{tabular}{|c|c|c|c|c|c|c|c|c|}
\hline \multirow{2}{*}{ No } & \multirow{2}{*}{ Pertanyaan } & \multicolumn{5}{|c|}{ Frekuensi Jawaban Responden } & \multirow{2}{*}{$\begin{array}{l}\text { Rata- } \\
\text { rata }\end{array}$} & \multirow{2}{*}{ Kriteria } \\
\hline & & STS & TS & $\mathbf{N}$ & $\mathbf{S}$ & SS & & \\
\hline 2 & $\begin{array}{l}\text { Saya memiliki wawasan tentang } \\
\text { produk yang dijual oleh Madanty } \\
\text { Fashion. }\end{array}$ & 0 & 0 & 14 & 75 & 51 & 4,26 & $\begin{array}{l}\text { Sangat } \\
\text { Tinggi }\end{array}$ \\
\hline 3 & $\begin{array}{l}\text { Saya dapat membedakan produk } \\
\text { Madanty Fashion dengan produk } \\
\text { clothing online lainnya. }\end{array}$ & 0 & 1 & 12 & 69 & 58 & 4,31 & $\begin{array}{l}\text { Sangat } \\
\text { Tinggi }\end{array}$ \\
\hline 4 & $\begin{array}{l}\text { Ketika mendengar mengenai clothing } \\
\text { online, saya mengingat Madanty } \\
\text { Fashion. }\end{array}$ & 0 & 1 & 16 & 74 & 49 & 4,22 & $\begin{array}{l}\text { Sangat } \\
\text { Tinggi }\end{array}$ \\
\hline 5 & $\begin{array}{l}\text { Ketika ditanya mengenai pilihan } \\
\text { produk clohing online, maka yang } \\
\text { muncul dalam benak saya adalah } \\
\text { Madanty Fashion. }\end{array}$ & 0 & 0 & 27 & 67 & 46 & 4,14 & Tinggi \\
\hline \multicolumn{7}{|c|}{ Rata-rata keseluruhan variabel brand awareness } & 4,27 & $\begin{array}{l}\text { Sangat } \\
\text { Tinggi }\end{array}$ \\
\hline
\end{tabular}

Nilai rata-rata terendah terdapat pada pernyataan "Ketika ditanya mengenai pilihan produk clohing online, maka yang muncul dalam benak saya adalah Madanty Fashion”. Hal ini menunjukan bahwa, Madanty Fashion belum menjadi pilihan utama dari responden yang berpartisipasi dalam pengisian kuesioner.

Tabel 11.

Deskripsi Jawaban Responden Terhadap Niat Beli

\begin{tabular}{|c|c|c|c|c|c|c|c|c|}
\hline \multirow{2}{*}{ No } & \multirow{2}{*}{ Pertanyaan } & \multicolumn{5}{|c|}{ Frekuensi Jawaban Responden } & \multirow{2}{*}{$\begin{array}{l}\text { Rata- } \\
\text { rata }\end{array}$} & \multirow{2}{*}{ Kriteria } \\
\hline & & STS & TS & $\mathbf{N}$ & $\mathbf{S}$ & SS & & \\
\hline 1 & $\begin{array}{l}\text { Setelah melihat iklan dari Madanty } \\
\text { Fashion, saya ingin mencari } \\
\text { informasi tentang produk yang } \\
\text { ditawarkan. }\end{array}$ & 0 & 1 & 6 & 63 & 70 & 4,44 & $\begin{array}{l}\text { Sangat } \\
\text { Tinggi }\end{array}$ \\
\hline 2 & $\begin{array}{l}\text { Saya akan mempertimbangkan } \\
\text { terlebih dahulu, sebelum membeli } \\
\text { produk dari Madanty Fashion. }\end{array}$ & 2 & 0 & 12 & 60 & 66 & 4,34 & $\begin{array}{l}\text { Sangat } \\
\text { Tinggi }\end{array}$ \\
\hline 3 & $\begin{array}{l}\text { Saya akan bertanya tentang detail } \\
\text { produk yang ditawarkan pada pihak } \\
\text { Madanty Fashion. }\end{array}$ & 0 & 1 & 5 & 65 & 69 & 4,44 & $\begin{array}{l}\text { Sangat } \\
\text { Tinggi }\end{array}$ \\
\hline 4 & $\begin{array}{l}\text { Saya tertarik untuk membeli produk } \\
\text { dari Madanty Fashion. }\end{array}$ & 0 & 1 & 9 & 73 & 57 & 4,32 & $\begin{array}{l}\text { Sangat } \\
\text { Tinggi }\end{array}$ \\
\hline 5 & $\begin{array}{l}\text { Saya akan membeli produk yang } \\
\text { ditawarkan oleh Madanty Fashion. }\end{array}$ & 0 & 1 & 15 & 69 & 55 & 4,27 & $\begin{array}{l}\text { Sangat } \\
\text { Tinggi }\end{array}$ \\
\hline \multicolumn{7}{|c|}{ Rata-rata keseluruhan variabel niat beli } & 4,36 & $\begin{array}{l}\text { Sangat } \\
\text { Tinggi }\end{array}$ \\
\hline
\end{tabular}


Dalam penelitian ini, variabel niat beli merupakan variabel terikat yang diukur dengan menggunakan 5 pernyataan yang berhubungan dengan niat beli Madanty Fashion. Tabel 11 menunjukkan niat beli secara keseuluruhan sangat tinggi, hal ini dapat dilihat dari keseluruhan rata-rata nilai niat beli yaitu 4,36. Nilai rata-rata tertinggi pada pernyataan" "Setelah melihat iklan dari Madanty Fashion, saya ingin mencari informasi tentang produk yang ditawarkan". Hal ini menunjukkan bahwa, responden yang berpartisipasi dalam pengisian kuesioner ingin mencari informasi lebih mengenai produk yang dipasarkan oleh Madanty Fashion. Nilai rata-rata terendah terdapat pada pernyataan "Saya akan membeli produk yang ditawarkan oleh Madanty Fashion". Hal ini menunjukan bahwa, responden yang berpartisipasi dalam pengisian kuesioner memiliki tingkat pembelian yang cenderung rendah pada produk Madanty Fashion.

Analisis statistik deskriptif berfungsi untuk menganalisis data dengan cara mendeskripsikan atau menggambarkan data yang telah terkumpul sebagaimana adanya tanpa bermaksud membuat kesimpulan yang berlaku untuk umum atau generalisasi. Hasil dari analisis statistik deskriptif yang diolah dengan bantuan software SPSS disajikan pada Tabel 12. sebagai berikut.

Tabel 12.

Hasil Analisis Statistik Deskriptif

\begin{tabular}{lccccc}
\hline & N & Minimum & Maximum & Mean & Std. Deviation \\
\hline Daya Tarik Iklan Online & 140 & 13 & 20 & 17,84 & 1,951 \\
Brand Awareness & 140 & 15 & 25 & 21,37 & 2,480 \\
Niat Beli & 140 & 9 & 25 & 21,83 & 2,507 \\
Valid N (listwise) & 140 & & & & \\
\hline
\end{tabular}

Sumber: Hasil pengolahan data primer, 2020

Statistik deskriptif pada Tabel 12. menunjukkan bahwa, nilai minimum dan maksimum variabel daya tarik iklan online sebesar 13 dan 20. Rata-ratanya (mean) sebesar 17,84 dengan standar deviasi sebesar 1,951. Hal ini berarti bahwa, terjadi perbedaan nilai daya tarik iklan online yang diteliti terhadap nilai rataratanya sebesar 1,951. Nilai minimum dan maksimum variabel brand awareness sebesar 15 dan 25. Rata- ratanya (mean) sebesar 21,37 dengan standar deviasi sebesar 2,480. Hal ini berarti bahwa, terjadi perbedaan nilai brand awareness yang diteliti terhadap nilai rata-ratanya sebesar 2,480. Nilai minimum dan maksimum variabel niat beli sebesar 9 dan 25. Rata-ratanya (mean) sebesar 21,83 dengan standar deviasi sebesar 2,507. Hal ini berarti bahwa, terjadi perbedaan nilai niat beli yang diteliti terhadap nilai rata- ratannya sebesar 2,507.

Berdasarkan hasil analisis jalur substruktur 1 seperti yang disajikan pada Tabel 13. maka, persamaan strukturnya adalah sebagai berikut :

$$
\begin{aligned}
& \mathrm{M}=\beta_{1} \mathrm{X}+\mathrm{e}_{1} \ldots . \\
& \mathrm{M}=0,631 \mathrm{X}+\mathrm{e}
\end{aligned}
$$


Tabel 13.

Hasil Analisis Jalur Persamaan Regresi 1

\begin{tabular}{|c|c|c|c|c|c|}
\hline Model & $\begin{array}{c}\text { Unstandardized } \\
\text { Coefficients }\end{array}$ & & $\begin{array}{c}\text { Standardized } \\
\text { Coefficients }\end{array}$ & $\mathbf{t}$ & Sig. \\
\hline & B & Std. Error & Beta & & \\
\hline (Constant) & 7,064 & 1,505 & & 4,692 & 0,000 \\
\hline $\begin{array}{l}\text { Daya Tarik Iklan } \\
\text { Online }\end{array}$ & 0,802 & 0,084 & 0,631 & 9,561 & 0,000 \\
\hline
\end{tabular}

Sumber: Hasil pengolahan data primer, 2020

Tabel 14. Hasil Analisis Jalur Persamaan Regresi 2

\begin{tabular}{llllll}
\hline \multirow{2}{*}{ Model } & \multicolumn{1}{c}{$\begin{array}{c}\text { Unstandardized } \\
\text { Coefficients }\end{array}$} & \multicolumn{5}{c}{$\begin{array}{c}\text { Standardized } \\
\text { Coefficients }\end{array}$} & t & Sig. \\
\cline { 2 - 7 } & \multicolumn{1}{c}{ B } & Std. Error & Beta & & \\
\hline (Constant) & 3,991 & 1,463 & & 2,727 & 0,007 \\
$\begin{array}{l}\text { Daya Tarik Iklan } \\
\text { Online }\end{array}$ & 0,507 & 0,098 & 0,395 & 5,193 & 0,000 \\
Brand Awareness & 0,411 & 0,077 & 0,407 & 5,353 & 0,000 \\
\hline $\mathrm{R}^{2}: 0,524$ & F Statistik : 75,410 & & Sig F :0,000 & &
\end{tabular}

Sumber: Hasil pengolahan data primer, 2020

Berdasarkan hasil analisis jalur substruktur 2 seperti yang disajikan pada Tabel 14. maka, persamaan strukturnya adalah sebagai berikut :

$$
\begin{aligned}
& \mathrm{Y}=\beta_{2} \mathrm{X}+\beta_{3} \mathrm{M}+\mathrm{e}_{2} \text {. } \\
& \mathrm{Y}=0,395 \mathrm{X}+0,407 \mathrm{M}+\mathrm{e}_{2}
\end{aligned}
$$

Hasil analisis jalur substruktur 1 dan substruktur 2 telah dihitung, maka dapat disusun model diagram jalur akhir. Nilai standard error dihitung terlebih dahulu sebelum menyusun model diagram jalur akhir, yaitu sebagai berikut:

$$
\begin{aligned}
& \mathrm{Pe}_{\mathrm{i}}=\sqrt{ } 1-\mathrm{R}_{\mathrm{i}}{ }^{2} \ldots \ldots \ldots \ldots \ldots \ldots \ldots \ldots . . . \\
& \mathrm{Pe}_{1}=\sqrt{1-R_{1}}=\sqrt{1-0,398^{2}}=0,917 \\
& \mathrm{Pe}_{2}=\sqrt{ } 1-R_{2}{ }^{2}=\sqrt{ } 1-0,524^{2}=0,851
\end{aligned}
$$

Berdasarkan perhitungan pengaruh error $\left(\mathrm{Pe}_{\mathrm{i}}\right)$, didapatkan hasil pengaruh error $\left(\mathrm{Pe}_{1}\right)$ sebesar 0,917 dan pengaruh error $\left(\mathrm{Pe}_{2}\right)$ sebesar 0,851 . Hasil koefisien determinasi total adalah sebagai berikut :

$$
\begin{aligned}
\mathrm{R}^{2}{ }_{\mathrm{m}} & =1-\left(\mathrm{Pe}_{1}\right)^{2}\left(\mathrm{Pe}_{2}\right)^{2} \ldots \ldots \ldots \\
& =1-(0,917)^{2}(0,851)^{2} \\
& =0,392
\end{aligned}
$$


Nilai determinasi total sebesar 0,392 mempunyai arti bahwa, sebesar 39,2 persen variasi daya tarik iklan online dipengaruhi oleh variasi brand awareness dan niat beli sedangkan, sisanya sebesar 60,8 persen dijelaskan oleh faktor lain yang tidak dimasukkan ke dalam model.

Diagram jalur telah digambarkan pada Gambar 1, maka dapat dihitung besarnya pengaruh langsung, pengaruh tidak langsung serta pengaruh total antar variabel daya tarik iklan online, brand awareness, dan niat beli. Perhitungan pengaruh antar variabel ditunjukkan dalam Tabel 15. berikut.

Uji sobel dihitung menggunakan aplikasi Microsoft Excel. Nilai standard error tidak langsung (indirect effect) atau Sab dihitung terlebih dahulu dengan rumus sebagai berikut:

$$
\begin{aligned}
& \mathrm{S} b_{1} b_{3}=\sqrt{ } b_{3}{ }^{2} S \mathrm{~b}^{2}+b 1^{2} \mathrm{Sb}^{2} \ldots \ldots \ldots \ldots \ldots \ldots \ldots \ldots . .(5) \\
& \mathrm{S} b_{1} b_{3}=\sqrt{ }(0,411)^{2}(0,084)^{2}+(0,802)^{2}(0,077)^{2} \mathrm{SSEP}^{2} \\
& \mathrm{~S} b_{1} b_{3}=\sqrt{0}, 001+0,003 \\
& \mathrm{~S} b_{1} b_{3}=0,063
\end{aligned}
$$

Untuk menguji signifikansi pengaruh tidak langsung maka, menghitung nilai $\mathrm{z}$ dari koefisien ab dengan rumus sebagai berikut :

$$
\begin{aligned}
& Z=\frac{\mathrm{b} 1 \mathrm{~b} 3}{\mathrm{Sb} 1 \mathrm{~b} 3} \ldots \ldots \ldots \ldots \ldots \ldots \ldots \\
& Z=\frac{(0,802)(0,411)}{0,063} \\
& Z=5,232
\end{aligned}
$$

Tabel 15.

Pengaruh Langsung, Pengaruh Tidak Langsung dan Pengaruh Total Daya Tarik Iklan Online (X), Brand Awareness (M) dan Niat Beli (Y)

\begin{tabular}{lccc}
\hline \multicolumn{1}{c}{ Pengaruh Variabel } & $\begin{array}{c}\text { Pengaruh } \\
\text { Langsung }\end{array}$ & $\begin{array}{c}\text { Pengaruh Tidak Langsung } \\
\text { Melalui Brand Awareness } \\
(\mathbf{M})=\left(\boldsymbol{\beta}_{\mathbf{1}} \mathbf{x} \boldsymbol{\beta} \mathbf{3}\right)\end{array}$ & $\begin{array}{c}\text { Pengaruh } \\
\text { Total }\end{array}$ \\
\hline $\begin{array}{l}\text { Daya Tarik Iklan Online - } \\
\text { Brand Awareness }\end{array}$ & 0,631 & - & 0,631 \\
$\begin{array}{l}\text { Daya Tarik Iklan Online-Niat } \\
\text { Beli }\end{array}$ & 0,395 & 0,256 & 0,651 \\
$\begin{array}{l}\text { Brand Awareness - Niat Beli } \\
\text { Sumber: Hasil pengolahan data primer, } 2020\end{array}$ & - & 0,407 \\
\hline
\end{tabular}

Hasil dari pengujian variabel mediasi didapatkan $\mathrm{Z}$ hitung sebesar 5,232 > 1,96 yang berarti variabel brand awareness memediasi variabel daya tarik iklan online terhadap niat beli produk Madanty Fashion.

Pengujian hipotesis pada pengaruh daya tarik iklan online terhadap brand awareness menunjukan bahwa daya tarik iklan online berpengaruh positif dan signifikan terhadap brand awareness. Hal ini ditunjukan dari perolehan nilai Sig. $t$ sebesar 0,000 dengan nilai koefisien beta 0,631. Nilai Sig. t 0,000<0,05. Apabila 
konsumen memiliki ketertarikan terhadap iklan maupun pesan iklan, maka akan mampu meningkatkan brand awareness pada suatu merek, begitu pula sebaliknya apabila konsumen tidak memiliki ketertarikan terhadap iklan maupun pesan iklan, maka brand awareness pada merek tersebut akan rendah. Hasil penelitian ini sesuai dengan penelitian sebelumnya yang dilakukan oleh (Charanah \& Njuguna, 2015) ; (Herdana, 2015); (Sukma et al., 2015) yang menyatakan bahwa efektifitas iklan berpengaruh secara positif dan signifikan terhadap brand awareness.

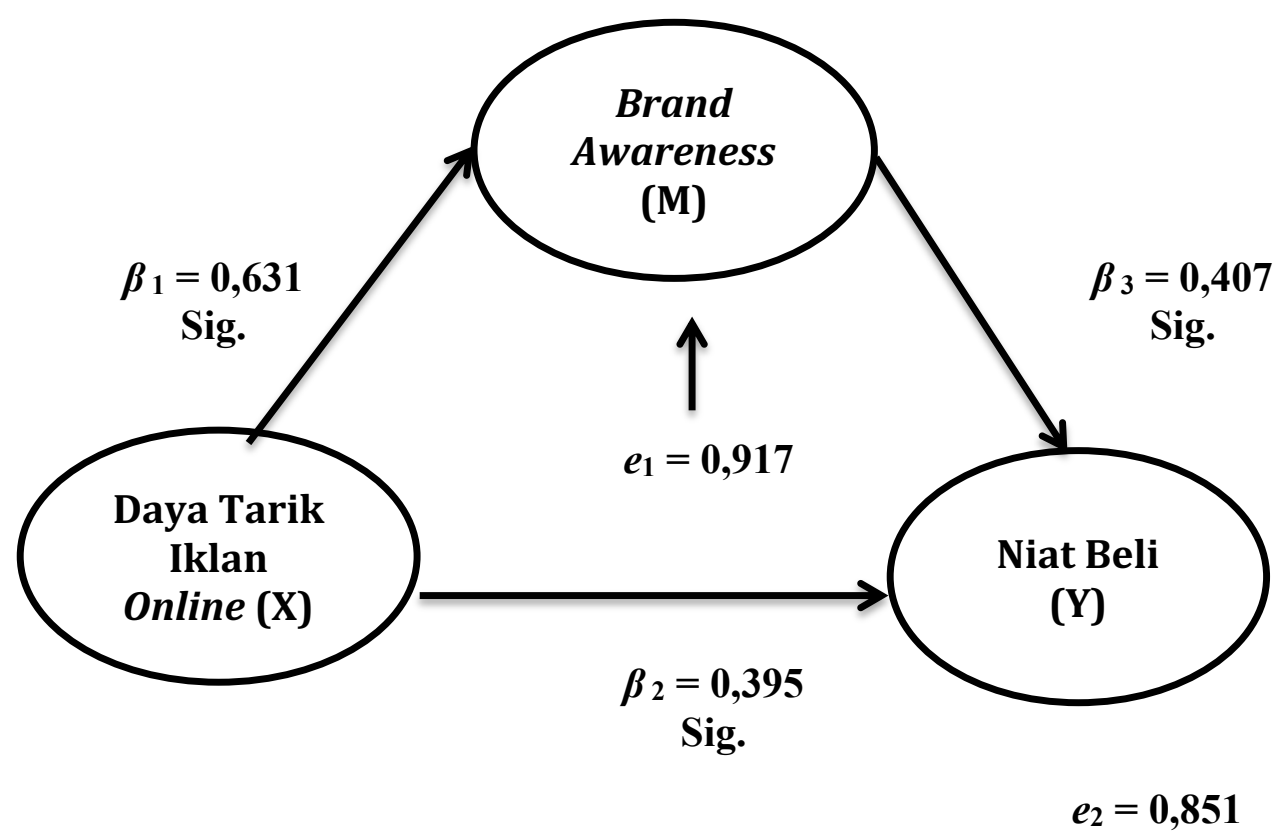

\section{Gambar 1. Validasi Model Diagram Jalur Akhir}

Sumber: Hasil pengolahan data primer, 2020

Pengujian hipotesis pada pengaruh daya tarik iklan online terhadap niat beli menunjukan bahwa daya tarik iklan online berpengaruh positif dan signifikan terhadap niat beli. Hal ini ditunjukan dari perolehan nilai Sig. $\mathrm{t}$ sebesar 0,000 dengan nilai koefisien beta 0,395 . Nilai Sig. t $0,000<0,05$. Pesan iklan yang baik akan menumbuhkan ketertarikan konsumen pada suatu produk, sehingga akan menumbuhkan niat beli terhadap produk tersebut, begitu pula sebaliknya apabila pesan iklan tidak menarik, maka niat beli terhadap produk tersebut akan rendah. Hasil penelitian ini sesuai dengan penelitian sebelumnya yang dilakukan oleh (Husein et al., 2016); (Nadu et al., 2014); (Huang, Ying-Fang Dang, 2014) yang menyatakan bahwa iklan berpengaruh positif dan signifikan terhadap niat beli.

Pengujian hipotesis pada pengaruh brand awareness terhadap niat beli menunjukan bahwa brand awareness berpengaruh positif dan signifikan terhadap niat beli. Hal ini ditunjukan dari perolehan nilai Sig. t sebesar 0,000 dengan nilai koefisien beta 0,407 . Nilai Sig. t $0,000<0,05$. Hal ini menunjukan bahwa, apabila merek yang memiliki brand awareness yang tinggi akan mampu mempengaruhi niat beli konsumen terhadap produk yang ditawarkan. Hasil penelitian ini sesuai 
dengan penelitian sebelumnya yang dilakukan oleh (Roozy et al., 2014) ; (Ehsan Malik et al., 2013); (Saad et al., 2012); dan (Yaseen \& Tahira, 2011) yang mengemukakan bahwa kesadaran merek (brand awareness) dapat mempengaruhi niat beli secara positif signifikan.

Peran brand awareness memediasi pengaruh daya tarik iklan online terhadap niat beli pada produk Madanty telah diuji dalam penelitian ini yang menunjukkan bahwa, brand awareness memediasi pengaruh daya tarik iklan online terhadap niat beli secara parsial. Uji sobel yang telah dihitung memperkuat hasil tersebut dengan nilai koefisien $\mathrm{z}$ yang diperoleh adalah 5,232 $>1,96$ dengan tingkat signifikansi $0,000<0,05$ sehingga, dapat dikatakan bahwa brand awareness memediasi pengaruh daya tarik iklan online terhadap niat beli. Hasil penelitian ini sesuai dengan penelitian sebelumnya yang dilakukan oleh (Prabawa et al., 2017); (Susilo \& Semuel, 2015) (Yudhiartika \& Haryanto, 2012) yang menyatakan bahwa brand awareness mampu memediasi hubungan iklan dengan niat beli secara positif dan signifikan. Dapat dikatakan bahwa, brand awareness memiliki peran yang penting dalam mempengaruhi persepsi konsumen pada daya tarik iklan online dan niat beli. Iklan yang menarik pada suatu produk akan diingat oleh konsumen yang nantinya akan mempengaruhi tindakan konsumen untuk membeli produk tersebut."

Penelitian ini memiliki implikasi secara teoritis dan praktis. Secara teoritis penelitian ini menunjukan bahwa, daya tarik iklan online dan brand awareness berpengaruh positif dan signifikan terhadap niat beli. Penelitian ini juga menunjukan bahwa, brand awareness mampu memediasi pengaruh daya tarik iklan online terhadap niat beli secara parsial. Dengan demikian, hasil penelitian ini memberikan dukungan empiris dan dapat dinyatakan memperkuat hasil-hasil studi terdahulu, sedangkan secara praktis dari penelitian ini diharapkan bagi perusahaan Madanty Fashion dapat lebih memperhatikan niat beli produk yang dipengaruhi oleh daya tarik iklan online dan juga brand awareness yang ditunjukan oleh koefisien determinasi sebesar 39,2 persen, namun perlu diperhatikan juga faktor lain yang dapat mempengaruhi niat beli. Penelitian ini juga diharapkan dapat memberikan kontribusi yang positif bagi perusahaan Madanty Fashion untuk terus berinovasi dan mengembangkan strategi perusahaannya.

Beberapa keterbatasan penelitian yang terdapat dalam penelitian ini adalah ruang lingkup penelitian ini hanya untuk pengguna media sosial Instagram di Kota Denpasar, sehingga hasil penelitian ini tidak dapat digeneralisir untuk wilayah yang lebih luas, serta penelitian ini hanya dilakukan dalam titik waktu tertentu (cross section), sedangkan waktu dan lingkungan setiap saat dapat berubah (dinamis), sehingga penelitian ini penting untuk dilakukan kembali di masa mendatang.

\section{SIMPULAN}

Daya tarik iklan online berpengaruh positif dan signifikan terhadap brand awareness Madanty Fashion. Dapat dikatakan bahwa, semakin menarik iklan yang ditayangkan, maka semakin tinggi brand awareness pada suatu merek, begitu pula sebaliknya apabila iklan yang ditayangkan tidak menarik, maka brand 
awareness pada merek tersebut akan rendah. Daya tarik iklan online juga berpengaruh positif dan signifikan terhadap niat beli Madanty Fashion. Dapat dikatakan bahwa, semakin baik pesan iklan yang ditayangkan, maka semakin meningkatkan niat beli terhadap suatu produk, begitu pula sebaliknya apabila pesan iklan tidak baik, maka niat beli terhadap produk tersebut akan rendah. Brand awreness berpengaruh positif dan signifikan terhadap niat beli Madanty Fashion. Dapat dikatakan bahwa, semakin kuat brand awareness yang diciptakan, maka semakin tinggi niat beli konsumen terhadap suatu produk. Brand awareness memediasi pengaruh daya tarik iklan online terhadap niat beli pada produk Madanty Fashion secara parsial. Dapat dikatakan bahwa, brand awareness memiliki peran yang penting dalam mempengaruhi persepsi konsumen pada daya tarik iklan online dan niat beli. Semakin menarik iklan yang ditayangkan, maka brand awareness pada suatu produk akan tinggi, sehingga akan mempengaruhi tindakan konsumen untuk membeli suatu produk.

Berdasarkan simpulan yang didapat, adapun beberapa saran yang dapat diberikan pada penelitian ini yaitu pihak Madanty Fashion disarankan untuk lebih meningkatkan niat beli pada produk yang ditawarkan Madanty Fashion yang dapat dilakukan dengan cara mengarahkan konsumen untuk membeli produk melalui pesan iklan yang menarik. Pihak Madanty Fashion juga disarankan untuk lebih menumbuhkan kesadaran merek (brand awareness) Madanty Fashion yang dapat dilakukan dengan cara meningkatkan penayangan iklan yang nantinya akan diingat oleh konsumen, sehingga dapat menjadi pilihan utama bagi konsumen. Saran bagi peneliti selanjutnya dapat menggunakan variabel lain sebagai variabel mediasi seperti Brand Equity, Brand Image, Brand Preference dan lain sebagainya, serta menambahkan variabel-variabel lain untuk meningkatkan niat beli pada suatu produk seperti Kualitas Produk, Green Marketing dan lain sebagainya. Disamping itu peneliti selanjutnya juga disarankan mampu memperluas cakupan penelitian ke wilayah lain serta menggunakan studi pada media online lainnya seperti Facebook, Twitter, Tiktok, dan lain sebagainya.

\section{REFERENSI}

Agustin Bayu Sugiardi, Dr. Harti, Dra, M. S. (2017). Pengaruh Iklan dan Atribut Produk Terhadap Brand Awareness Pada Produk Hufagripp. Jurnal Pendidikan Tata Niaga (JPTN), 03(03).

Barr, S. (2007). Factors Influencing Environmental Attitudes and Behaviors. Environment and Behavior, 39(4), 435-473. https://doi.org/10.1177/0013916505283421

Bülbül, C., \& Menon, G. (2010). The power of emotional appeals in advertising: The influence of concrete versus abstract affect on time-dependent decisions. Journal of Advertising Research, 10(1), 169-180. https://doi.org/10.2501/S0021849910091336

Cat, N. (2020). (Pengguna Instagram Di Indonesia Pada Periode Januari-Mei 2020. Good News From Indonesia. https://www.goodnewsfromindonesia.id 
Charanah, J., \& Njuguna, R. K. (2015). The Effects of Promotional Mix Tools on Brand Equity Among Hospitals in Nairobi County. Journal of Sales, Retailing and Marketing, 4(6), 45-52.

Clark, C. R., Doraszelski, U., \& Draganska, M. (2009). The effect of advertising on brand awareness and perceived quality: An empirical investigation using panel data. Quantitative Marketing and Economics, 7(2), 207-236. https://doi.org/10.1007/s11129-009-9066-z

Dewa, C. B. (2015). Pengaruh Country Of Origin Produk Televisi LG Terhadap Niat Beli Konsumen Dengan Ekuitas Merek Sebagai Variabel Pemediasi. Jurnal Bianglala Informatika, 3(1), 74-82.

Ehsan Malik, M., Mudasar Ghafoor, M., Kashif Iqbal, H., Riaz, U., ul Hassan, N., Mustafa, M., \& Shahbaz, S. (2013). Importance of Brand Awareness and Brand Loyalty in assessing Purchase Intentions of Consumer. International Journal of Business and Social Science, 4(5), 167-171.

Erdogmus, I. E., \& Cicek, M. (2012). The Impact of Social Media Marketing on Brand Loyalty. Procedia - Social and Behavioral Sciences, 58, 1353-1360. https://doi.org/10.1016/j.sbspro.2012.09.1119

Fitri Anggraini Gunawan, D. D. (2014). Analisis Pengaruh Iklan Televisi Dan Endorser Terhadap Purchase Intention Pond'S Men Dengan Brand Awareness Sebagai Variabel Intervening. Jurnal Manajemen Pemasaran Petra, 2(1), 1-14.

Herdana, A. (2015). Analisis Pengaruh Kesadaran Merek (Brand Awareness) Pada Produk Asuransi Jiwa Prudential Life Assurance (Studi Pada Pru Passion Agency Jakarta). Jurnal Riset Bisnis Dan Manajemen, 3(1), 1-18.

Huang, Ying-Fang Dang, H. S. (2014). An Empirical Analysis on Purchase Intention on Coffee Beverage in Taiwan. European Journal of Business and ManagementOnline), 6(36), 182-196.

Husein, A., Zulkarnain, Z., \& Taufiqurrahman, T. (2016). Analisis Pengaruh Iklan dan Celebrity Endorser Terhadap Citra Merek dalam Meningkatkan Minat Beli Shampoo Pentene Pada Masyarakat Kota Pekanbaru. Jurnal Online Mahasiswa Fakultas Ekonomi Universitas Riau, 4(1), 243-256.

Iwan, \& Nainggolan, K. (2017). Pengaruh Celebrity Endorser, Brand Awareness Dan Harga Produk Terhadap Minat Beli Mie Suksess (Studi Empiris Pada Penduduk Kecamatan Pinang-Kota Tangerang). Jurnal Cakrawala, 17(2), 146-155. 
Kotler, P. dan G. A. (2018). Principles of Marketing. (17th ed.). Pearson.

Kristanto, H., \& Karina M.R. Brahmana, R. (2016). Pengaruh Product Placement Pada Film Indonesia Terhadap Brand Awareness dan Purchase Intention Masyarakat Surabaya. Jurnal Manajemen Pemasaran, 10(1), 20-26. https://doi.org/10.9744/pemasaran.10.1.20-26

Nadu, T., S, H. K., \& Kurup, S. K. (2014). Effectiveness of Television Advertisement on Purchase Intention. International Journal of Innovative Research in Science, Engineering and Technology, 3(2), 9416-9422.

Nwankwo, D. B. E., Aboh, D. J. U., Obi, T. C., Agu, S. A., \& Agbor, D. N. S.-. (2013). Influence of Advertising Appeals and Personality on Telecoms Consumption Preferences in Nigeria. International Journal of Academic Research in Business and Social Sciences, 3(9), 229-237. https://doi.org/10.6007/ijarbss/v3-i9/205

Petahiang, I. L., Mekel, P., \& Worang, F. G. (2015). The Influence of Brand Awareness and Perceived Risk Toward Consumer Purchase Intention on Online Store ( Case Study of the Customer At Feb Unsrat Manado ). Jurnal Berkala Ilmiah Efisiensi, 15(04), 12.

Prabawa, K., Sukawati, T., \& Setiawan, P. (2017). Peran Brand Awareness Dalam Memediasi Hubungan Iklan Dan Personal Selling Dengan Niat Beli. EJurnal Manajemen Universitas Udayana, 6(2), 255107.

Roozy, E., Arastoo, M. A., \& Vazifehdust, H. (2014). Effect of Brand Equity on Consumer Purchase Intention. Indian J.Sci.Res, 6(1), 212-217.

Saad, S., Shah, H., Aziz, J., Jaffari, A., Waris, S., \& Ejaz, W. (2012). The Impact of Brands on Consumer Purchase Intentions. Asian Journal of Business Management 4(2): , 4(2), 105-110.

Shimp, T. A. (2014). Komunikasi Pemasaran Terpadu dalam Periklanan dan Promosi. Salemba Empat.

Sukma, F., Sarma, M., \& Syamsun, M. (2015). Efektivitas Iklan dalam Menumbuhkan Brand Awareness SMA Sampoerna. MANAJEMEN IKM: Jurnal Manajemen Pengembangan Industri Kecil Menengah, 10(2), 182193. https://doi.org/10.29244/mikm.10.2.182-193

Suprapti. (2010). Perilaku Konsumen Pemahaman Dasar Dan Aplikasinya Dalam Strategi Pemasaran. Udayana University Press.

Susilo, I., \& Semuel, H. (2015). Analisa Pengaruh Emotional Marketing Terhadap Purchase Intention Melalui Brand Awareness Pada Produk Dove Personal 
Care Di Surabaya. Jurnal Manajemen Pemasaran, 9(1), 23-34. https://doi.org/10.9744/pemasaran.9.1.23-34

Wen, L., \& Li, S. (2013). A Study on the Relationship Amidst Health Consciousness, Ecological Affect, and Purchase Intention of Green Production. The International Journal of Organizational Innovation, 5(April 2013), 124-138. http://www.ijoi-online.org/attachments/article/34/FINAL ISSUE VOL 5 NUM 4 APRIL 2013.pdf\#page=124

Wibowo, B. M., \& Nurhadi, M. M. (2017). Pengaruh Kualitas Produk, Efektivitas Iklan, Dan Celebrity Endorser Terhadap Minat Beli Sandal (Studi Pada Sandal Homyped Versi Iklan Raffi Ahmad Dan Soimah di Fakultas Ekonomi Universitas Negeri Yogyakarta). 1, 1-11.

Wicaksono, M., \& Seminari, N. (2016). Pengaruh Iklan Dan Word Of Mouth Terhadap Brand Awareness Traveloka. E-Jurnal Manajemen Unud, 5(8), 5098-5127.

Yaseen, N., \& Tahira, M. (2011). Impact of Brand Awareness, Perceived Quality and Customer Loyalty on Brand Profitability and Purchase Intention: A Resellers ' View. Interdisciplinary Journal of Contemporary Research in Business, 3(8), 833-839.

Yudhiartika, D., \& Haryanto, J. (2012). Pengaruh Personal Selling, Display, Promosi Penjualan Terhadap Kesadaran Merek Dan Intensi Membeli Pada Produk Kecantikan Ponds. Buletin Studi Ekonomi, 17(2), 142-156. 